\title{
DESAIN MOTIF TENUN SONGKET MINANGKABAU DI USAHA RINO RISAL KECAMATAN KOTO TANGAH KOTA PADANG
}

\author{
Widi Aliffa Izzara ${ }^{1 *}$, Weni Nelmira ${ }^{2 *}$ \\ Jurusan Ilmu Kesejahteraan Keluarga Program Studi Pendidikan Kesejahteraan Keluarga \\ Fakultas Pariwisata dan Perhotelan \\ Universitas Negeri Padang \\ Jl. Prof. Dr. Hamka, Air Tawar, Kel. Air Tawar Barat, Kec. Padang Utara, Kota Padang, 25171 \\ Sumatera Barat. Indonesia \\ Email: widi.aliffa@gmail.com
}

\begin{abstract}
Abstrak
Masalah dalam penelitian ini yaitu masyarakat Kecamatan Koto Tangah selama ini hanya mampu menikmati tenunan songket Minangkabau secara fungsional saja tanpa mengetahui nama dan bentuk motif. Penelitian ini bertujuan untuk mendeskripsikan desain motif dan bentuk motif tenun songket Minangkabau di Kecamatan Koto Tangah Kota Padang. Jenis penelitian ini adalah deskriptif kualitatif dengan jenis data berupa data primer dan data sekunder, Teknik dalam mengumpulkan data pada penelitian ini yaitu melalui observasi, wawancara dan dokumentasi. Teknik analisis data dilakukan dengan menggunakan reduksi data, penyajiaan data dan pengambilan kesimpulan. Hasil penelitian ini menunjukan bahwa motif yang terdapat pada Usaha Rino Risal yang sering digunakan terdiri dari 14 motif yaitu, motif pucuak rabuang, saik kalamai, buah palo, balah kacang, salapah, api, tirai, biku, itiak pulang patang, anyam, bada mudiak, saluak laka, cukia baserak, sirangkak.
\end{abstract}

Kata Kunci: motif, tenun, songket minangkabau.

\begin{abstract}
The problem in this research is that the people of Koto Tangah Subdistrict have only been able to enjoy the Minangkabau songket weave functionally without seeing the name and shape of the motif. This study aims to describe the design of the motifs and the shape of the Minangkabau songket weaving motifs in Koto Tangah sub district, Padang city. This type of research is descriptive qualitative with the type of data in the form of primary data and secondary data. Techniques in collecting data in this study were observation, interviews and documentation. The data analysis technique was carried out by using data reduction, data presentation and data retrieval. The results of this study indicate that the motives found in the Rino Risal Business which are often used consist of 14 motives, namely motives pucuak rabuang, saik kalamai, buah palo, balah kacang, salapah, api, tirai, biku, itiak pulang patang, anyam, bada mudiak, saluak laka, cukia baserak sirangkak.
\end{abstract}

Keywords: motif, weaving, sogket minangkabau

\section{PENDAHULUAN}

Kota Padang merupakan kota yang memiliki banyak industri kreatif, salah satunya yaitu Usaha Rino Risal di Kecamatan Koto Tangah yang menonjolkan hasil karya kerajinan tenun songket Minangkabau. Tenun merupakan hasil karya kegiatan masyarakat berupa kain dari bahan yang digabung dari benang (kapas, sutra, dan sebagainya) caranya yaitu memasukkan bahan secara melintang pada lusi. songket adalah kain yang ditenun dengan memanfaatkan benang emas atau benang perak yang dihasilkan oleh daerah tertentu saja.

Masyarakat Kecamatan Koto Tangah selama ini hanya mampu menikmati tenunan songket Minangkabau secara fungsional saja tanpa mengetahui tentang motif (Mikke Susanto,2002) menuliskan bahwa, motif adalah pattern, corak, gaya. Sedangkan Motif hias adalah bentuk hiasan pada kain, bagian rumah dan sebagainya. Secara umum, batasan tentang motif memang demikian, tetapi pada ornamen, motif memiliki arti tersendiri.

Motif terdiri atas unsur kerangka atau subjek, skala atau proporsi, dan komposisi.Motif menjadi tumpuan atau pokok dari suatu pola. Motif itu mengalami proses penyusunan dan dibuatkan secara berulang-ulang sehingga diperoleh sebuah pattern. Pattern itulah yang nantinya akan dibuat pada benda lain yang nantinya menjadi sebuah bentuk (Setiati,2008) Ragam-hias atau motif songket Sumatera Barat yang disebut cukie tidak hanya sebagai hiasan dan ornamen. Songket Minangkabau memiliki beberapa motif tradisional yang menjadi ciri khas budaya wilayah pembuat kain tenun tersebut. Motif songket berbentuk biasanya seperti geometris, salur dan reka tumbuhan karena alam 
dianggap sebagai bentuk pokok dan penting bagi umat manusia. Namun ada juga motif yang senama dengan nama kue khas Melayu seperti serikaya, wajik, dan tepung talam, yang ditaksir merupakan penganan kegemaran raja (Basuki,2014). Penelitian sekarang ini bertujuan untuk menggambarkan desain motif dan bentuk motif tenunan songket Minangkabau di Usaha Rino Risal Kecamatan Koto Tangah Kota Padang Sumatera Barat.

\section{KAJIAN TEORI}

Tenun adalah teknik dalam pembuatan kain yang dibuat dengan prinsip yang sederhana seperti menggabungkan benang secara memanjang dan melintang. Dengan kata lain bersilangnya benang lusi dan pakan secara bergantian. (Budiyono dkk, 2008). Songket yaitu salah satu pakaian yang dikenakan oleh manusia merupakan karya seni yang indah, karena fungsinya tidak hanya sebagai pelindung, maupun dekorasi, melainkan untuk memperlihatkan suatu tujuan dengan daya tariknya (Kartiwa, 1986)

Saat ini kain songket tenun tradisional Minangkabau diproduksi secara aktif hanya di daerah Silungkang dan Pandai Sikek, jika tenun songket diproduksi Studio Songket Loom Sumatera diletakkan disamping kain songket pembuatan daerah lain di Sumatera Barat seperti Silungkang dan Pandai Sikek maka perbedaan itu jelas terlihat dari segi bentuk produk yang dihasilkannya, terutama dari tekstur seperti halus, licin, tebal pada permukaan kain, Menurut Biranul (2012).

Doni Rahman(2015) Menuliskan desain merupakan rancangan atau rencana yang menjadi dasar dalam membuat benda atau karya, Mikke Susanto (2002) dalam buku Diksi Rupa menyatakan bahwa, motif adalah pattern, corak, ragam. Motif hias adalah bentuk hiasan pada kain, bagian rumah dan lainnya. Secara umum, batasan mengenai motif memang demikian, tetapi pada hiasan, motif mempunyai arti khusus. Menurut Ernawati \& Weni Nelmira (2008) "Secara umum motif-motif yang ada disekitar kita berasal dari 4 macam bentuk ragam hias. Jenis-jenis ragam hias ini adalah: (1) Motif Naturalis, yaitu motif yang dihasilkan berdasarkan bentu yang ada di sekitar alam . (2) Motif Geometris, yaitu motif yang bisa di ukur. (3) Motif Dekoratif, yaitu motif terbaru yang telah di stilasi dari bentuk naturalis dan geometris, (4) Motif Abstrak, yaitu motif yang tidak beraturan.

Menurut Biranul (2012) menyatakan "penamaan macam motif yang diciptakan diatas sehelai kain tidak sekedar diberi nama sebagai pembeda antara satu motif dengan motif lainnya dan tanda, tetapi berasal dari sesuatuyang mendalangi pemikiran penciptanya. Latar belakang pemikiran tersebut berasal dari reka bentuk alam, terutama bentuk tumbuhan yang ada disekitar kita, diambil secara utuh atau bahagian saja. Juga ada bentuk motif berdasarkan nama binatang, berrbentuk geometris, petatah petitih dan kata-kata adat ". Sesuai dengan Nusyirwan (1982) menjelaskan “ Jenis ragam hias yang dijumpai itu selalu berkisar pada tumbuhan, hewan dan alam. Untuk jenis alam tumbuhan dijumpai berupa kaluak paku, bungo kalayau, tampuak manggih, pucuak rabuang, dan lainlain. Alam hewan kita temukan nama itik pulang patang ,ula gerang, lintandu bapatah dan lain-lain. Dan gejala alam berupa saik galamai, kaluak ampek puluah, bareh randang, tali burung, dan lain-lain"

\section{METODE PENELITIAN}

Berdasarkan tujuan penelitian dan permasalahan yang telah dijabarkan, maka penelitian yang peneliti gunakan yaitu penelitian kualitatif dengan pendekatan studi kasus, yaitu menggambarkan atau mengungkapkan fenomena yang terjadi dengan cara ilmiah atau objektif, yang diangkat dari pemahaman akan sesuatu yang menarik perhatian, peristiwa konkret, proses sosial yang terjadi atau pengalaman orang yang menjadi latar sebuah kasus.

Jenis data yang diambil yaitu berupa data sekunder dan data primer. Menurut Prastowo (2016) "Data primer merupakan data yang di ambil dari sumber pertama”. Sedangkan data sekunder menurut Prastowo (2016) "data yang di dapat bukan dari sumber pertama tetapi dari sumber kedua, ketiga, dan seterusnya". Sumber data yang digunakan dalam penelitian ini adalah foto, kata-kata , tindakan dan sumber tertulis. Informan didalam penelitian ini adalah orang yang ada pada daerah penelitian artinya orang yang dapat memberikan informasi tentang kondisi situasi latar penelitian.

Alat dan teknik dalam pengumpulan data yang dilakukan melalui wawancara, observasi, dan dokumentasi. Teknik analis data yang dilakukan adalah data reduction (reduksi data), data display (penyajian data), penarikan kesimpulan /verivikasi..

\section{HASIL DAN PEMBAHASAN}

\section{Hasil}

\section{1). Desain Motif}

Ulasan dari semua wawancara dengan informan dan triangulasi maka dapat disimpulkan bahwa desain motif adalah rencana dalam menciptakan corak hiasan yang akan di jadikan sebuah kain. Desain terdiri dari unsur garis, bentuk, figur yang disusun agar terlihat indah. Desain motif di Usaha Rino Risal yaitu motif yang 


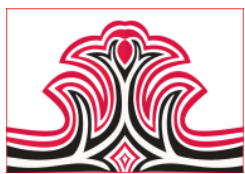

terinspirasi dari alam dan keseharian masyarakat Minangkabau. seperti dari tumbuhan, hewan, makanan khas Minangkabau. Sesuai dengan pemikiran Minangkabau alam takambang menjadi guru. Tenunan songket biasanya terdiri dari bagian kepala kain, badan kain dan kaki/tepi kain. Pada Usaha Rino Risa Desain motif bagian kepala dan badan selalu diubah agar konsumen tertarik, pada bagian kaki/ tepi kain tidak pernah diubah karena merupakan ciri khas dari tempat Usaha Rino Risal. Masing-masing bagian memiliki pola hias tersendiri.

Pada desain motif kepala songket di Usaha Rino Risal ditempatkan motif berukuran besar dengan pola hias pinggiran karena kepala songket merupakan inti songket yang harus ditonjolkan. Biasanya jika songket dijadikan rok, kepala songket diletakkan pada bagian depan sehingga rok menjadi lebih menarik. Motif utama pada kepala songket yaitu pucuak rabuang.

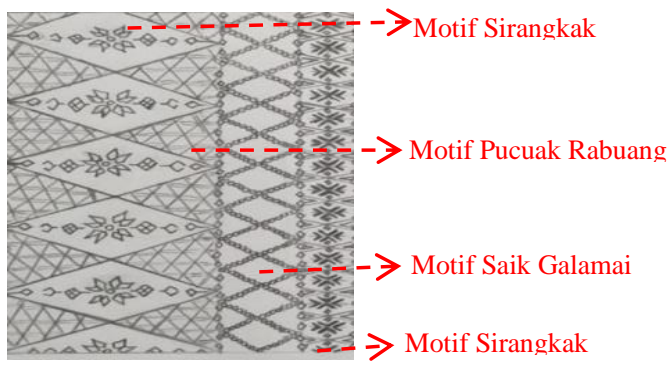

Gambar 1. Desain Motif Kepala Songket

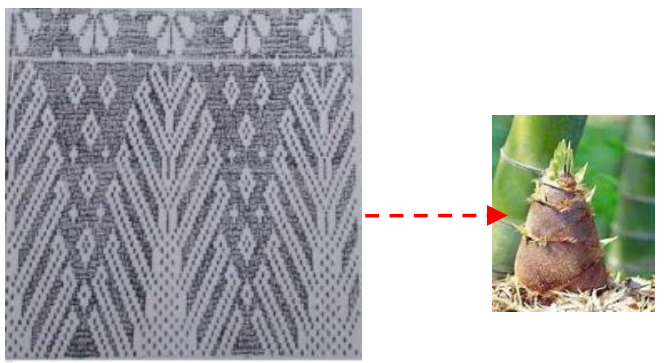

Gambar 2. Motif "Pucuk Rebung"

Pada desain motif badan songket di Usaha Rino Risal ditempatkan motif berukuran sedang yang memiliki pola hias mengisi bidang. karena badan songket merupakan bagian sebagian besar pada songket. Biasanya motif pada badan songket yaitu salapah, saik galamai, tirai, anyam, balah kacang, sirangkak, cukia baserak.
Gorga : Jurnal Seni Rupa

Volume 10 Nomor 02 Juli-Desember 2021 p-ISSN: 2301-5942 | e-ISSN: 2580-2380

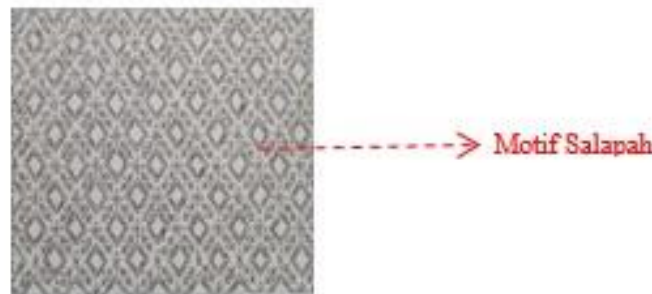

Gambar 3. Desain Motif Badan Songket

Pada desain motif kaki/ tepi songket di Usaha Rino Risal ditempatkan motif berukuran kecil dengan pola hias pinggiran karena kaki/tepi kain songket merupakan ciri khas songket di Usaha Rino Risal yang selama ini belum diubah. Motif utama pada kepala songket yaitu pucuak rabuang.

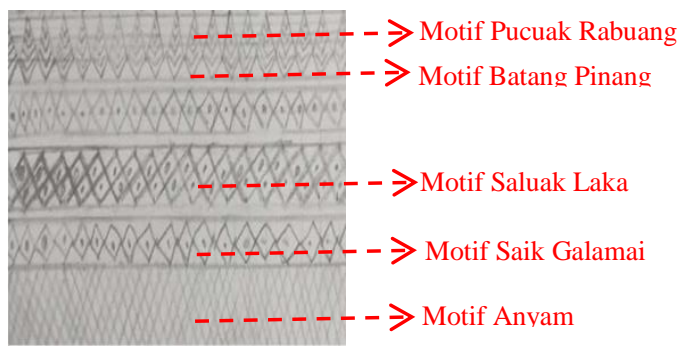

Gambar 4. Desain Motif Kaki/Tepi Songket

Berdasarkan wawancara yang telah penulis lakukan, pengrajin diberikan bermacam desain motif yang diberikan sebagai pedoman dalam pembuatan songket. Desain tersebut juga berupa titik-titik agar mempermudah penenun dalam membuat songket. Berikut beberapa bentuk desain motif yang ada pada pengerajin.
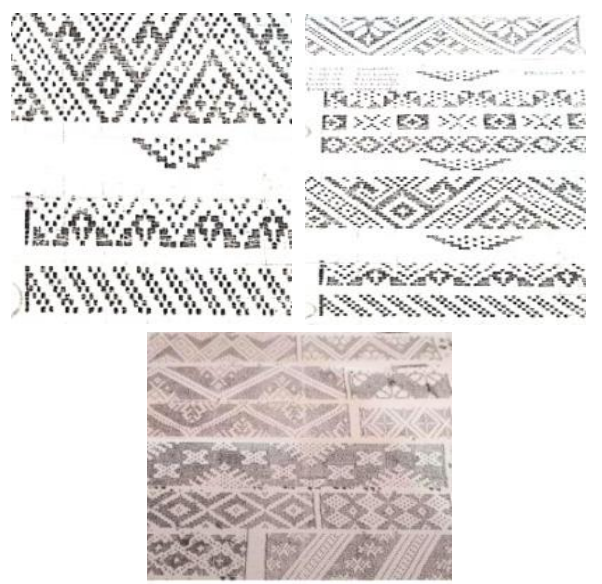

Gambar 5. Macam Desain Motif

Tenun songket di Usaha Rino Risal memiliki beragam motif pada bagian kepala dan badan kain dan pada kaki/tepi kain merupakan cirikhas bagi tempat Usaha Rino Risal. Warna songket beragam. Berikut bentuk desaian motif yang telah diproduksi oleh Usaha Rino Risal. 

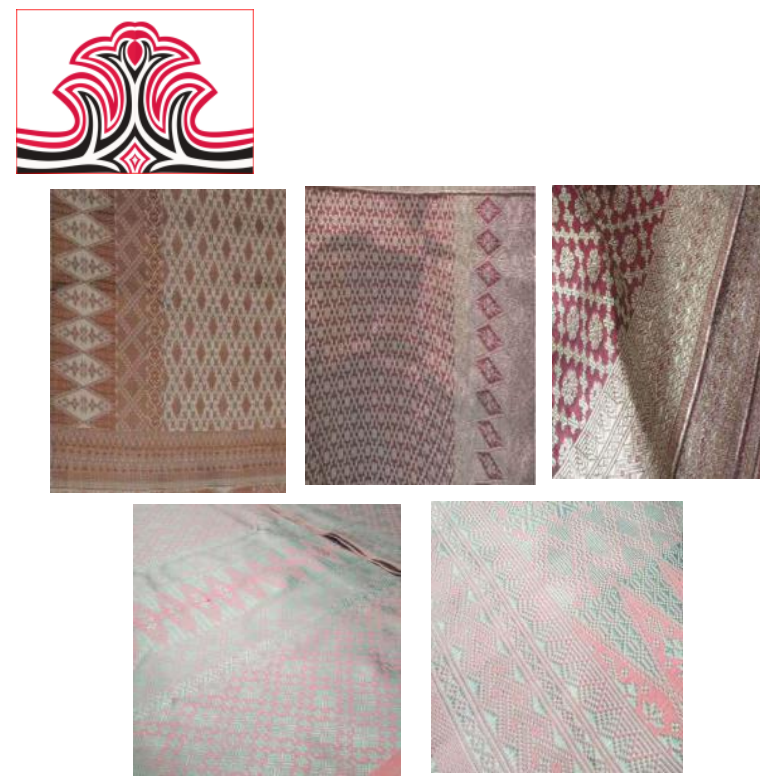

Gambar 6. Desain Motif yang Beragam

\section{2). Bentuk Motif}

Ulasan dari semua wawancara dengan informan dan triangulasi maka dapat disimpulkan bahwa bentuk motif merupakan gambaran atau wujud dari ragam hias. Bentuk motif yang ada pada tenun songket di Usaha Rino Risal berasal dari alam dan keseharian masyarakat Minangkabau. Berdasarkan hasil wawancara yang telah peneliti lakukan, pemilik usaha mengumpulkan bermacam bentuk motif berupa fotokopian dan dari internet. Motif tersebut disusun menjadi desain motif dalam pembuatan satu helai kain songket.

Berikut ini beberapa bentuk motif yang terdapat pada kain songket di Usaha Rino Risal

\section{(1) Motif Pucuak Rabuang}

Motif pucuk rabuang berbentuk segitiga yang diambil dari bentuk tunas bambu. Pucuk rabuang adalah tunas bambu yang baru muncul dari umbinya. Biasanya pucuk rabuang dijadikan makanan pelengkap juga makanan adat pada acara tertentu. makna motif pucuk rabuang adalah kita harus hidup seperti sifat bambu yang sangat fungsional. Bambu saat masih muda bisa dijadikan untuk makanan. Ketika sudah besar dapat dijadikan sebagai dinding rumah dan ketika tua dapat dijadikan sebagai tempat saluran air dan sebagainya. Dengan menganalogikan kehidupan bambu maka kita diharapkan agar bisa berguna untuk siapapun dari muda sampai tua.

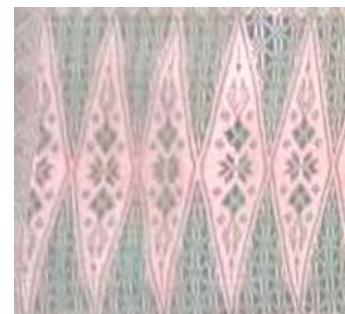

Gambar 7. Bentuk Motif Pucuk Rebung
Gorga : Jurnal Seni Rupa

Volume 10 Nomor 02 Juli-Desember 2021

p-ISSN: 2301-5942 | e-ISSN: 2580-2380

\section{(2) Motif Saik Galamai}

Motif saik galamai merupakan motif geometris yang berbentuk seperti segi empat belah ketupat. Galamai adalah makanan dengan tekstur lengket seperti dodol yang bisa ditemui di daerah Minangkabau sebagai oleholeh. Makanan ini juga ada pada acara adat. Dalam bahasa Indonesia saik mengartikan sayatan atau potongan. Penyajian galamai biasanya dengan cara dipotong kecil berbentuk segiempat. Makna motif ini yaitu agar kita menanam sifat hemat dan tidak boros dalam diri kita, hal ini dapat dilihat dari cara makan gulamai yang sepotong demi sepotong. Sesuai dengan falsafah minang bakulimek sabalun habih ingek-ingek sabalun kanai.

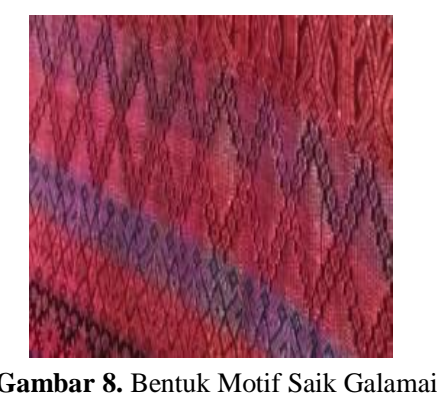

\section{(3) Motif Buah Palo}

Motif buah palo berbentuk persegi empat belah ketupat dengan bagian dalam bergaris seperti bagian dalam buah palo saat dibelah dua. Buah palo memeliki makna cita-cita yang luhur bagaikan ombak di Pantai yang bergelombang

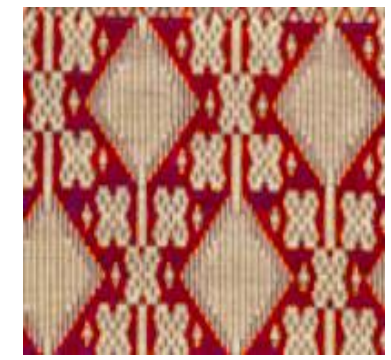

Gambar 9. Bentuk Motif Buah Palo

\section{(4) Motif Balah Kacang}

Motif balah kacang berbentuk seperti kulit kacang yang disusun. Balah kacang yaitu belahan kacang. Beberapa kacang jika direbus akan tedepas dari kulitnya dan jika direbus akan meletup-Ietup. Sifat tersebut mengajarkan kita untuk tidak lupa asal mula kita dan tidak seperti kacang meletup yang tidak mempunyai tujuan dan arah dalam melakukan suatu pekerjaan. 

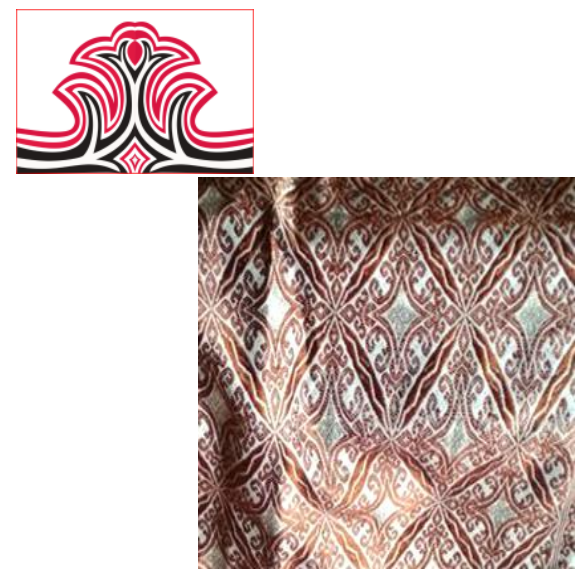

Gambar 10. Bentuk Motif Balah Kacang

(5) Motif Salapah

Motif salah berbentuk seperti anyaman yang menyilang lebih besdar. Salapah merupakan dompet kecil yang dibuat dari anyaman daun pandan dan kain. Dahulu, salapah dibawa ke mana saja oleh masyarakat Pandaisikek dan beriskani siriah langkok. Jika bertemu, sebelum memulai perbincangan mereka akan membuka salapah dan menawarkannya kepada lawan bicaranya dan begitu juga sebaliknya. Motif ini mengajarkan kita bahwa sebagai manusia kita harus saling berbagi apa yang kita punya kepada orang lain. Nilai yang dikandung dari motif salapah adalah solidaritas dan tenggang rasa yang harus dijunjung tinggi bersama seperti dalam pepatah Minangkabau lamak dek awak katuju dek urang.

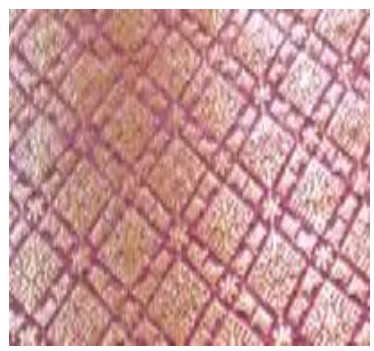

Gambar 11. Bentuk Motif Salapah

(6) Motif Tirai

Tirai merupakan hiasan dibuat dari kain yang diletakkan pada pintu, dinding, dan lainnya yang berfungsi untuk menambah keindahan sebagai lambang kemewahan didalam upacara adat.

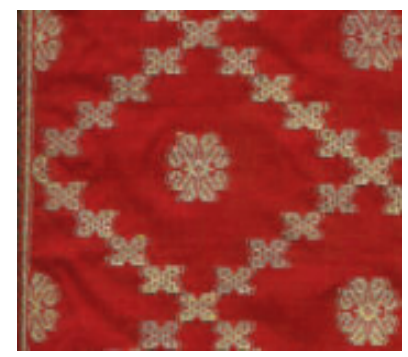

Gambar 12 Bentuk Motif Tirai

\section{(7) Motif Batang Pinang}

Batang pinang memiliki bentuk lurus memiliki makna selalu jujur dalam kehidupan. Bentuknya seperti 2 garis lurus tanpa ada potongan.
Gorga : Jurnal Seni Rupa

Volume 10 Nomor 02 Juli-Desember 2021 p-ISSN: 2301-5942 | e-ISSN: 2580-2380

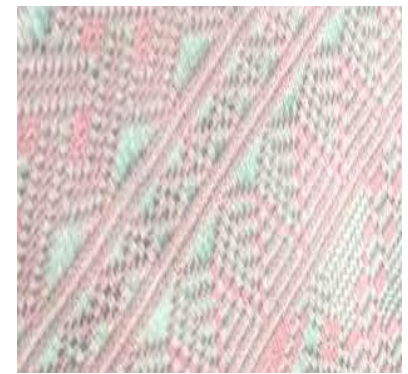

Gambar 13. Bentuk Motif Batang pinang

\section{(8) Motif Itiak Pulang Patang}

Motif itik berbentuk seperti gelombang yang turun naik. Itik merupakan bangsa unggas yang hidup di darat, bisa berenang, posturnya seperti angsa tapi lebih kecil dan termasuk binatang peliharaan. Motif ini menceritakan tentang perilaku itik saat pulang dan mencari makan yang selalu terlihat rapi dalam satu barisan yang terjaga keteraturannya. Motif ini memberikan pesan bahwa solidaritas dalam kelompok harus terjaga. Di samping itu, motif ini menjelaskan bahwa masyarakat harus menaati pemimpin yang berdiri di depan agar kehidupan dalam berkelompok tetap harmonis. Kawanan itik selalu digiring oleh itik jantan. Dengan kata lain, pemimpin barisan adalah itik jantan. Hal ini merupakan jati diri didalam kehidupan masyarakat Minangkabau. Sistem kekerabatan Minangkabau menganut sistem matrilinial yaitu garis ibu, tetapi tanggung jawab sosial mengenai kehidupan dan keturunan adalah saudara laki-laki ibu atau lebih dikenal dengan sebutan mamak. Disamping itu, didominassi di setiap suku adalah laki-laki yang disebut dengan penghulu.

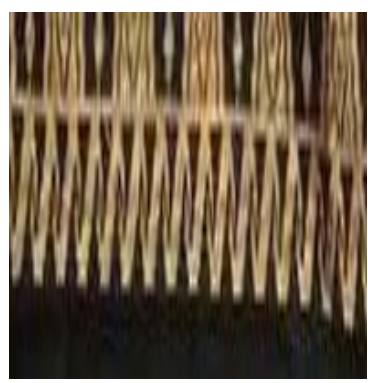

Gambar 14 Bentuk Motif Itiak Pulang Patang (Sumber: Ratih Ratnasari, 2020)

\section{(9) Motif Anyam}

Anyam merupakan lembaran yang tindih menindih dan silang menyilang. Anyam memiliki makna sebagai lambang kebersamaan dan pemersatu suatu kelompoka masyarakat. 

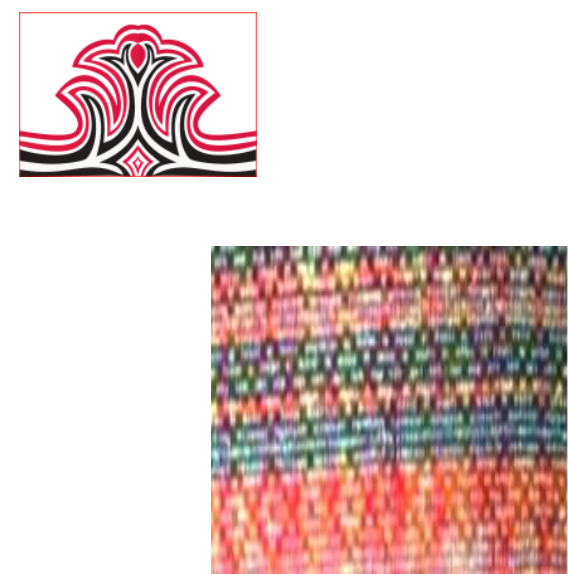

Gambar 14 Bentuk Motif Anyam

\section{(10) Motif Bada Mudiak}

Motif bada mudiak berbentuk seperti kepala panah yang berderet ke satu arah. Dua garis yang menyatu membentuk sudut $160^{\circ}$. Bada adalah ikan kecil disebut teri dan mudik adalah arah mudik(kehulu). kehidupan ikan kecil yang bergerak kehulu menyongsong air yang jernih. Bada mudiak memiliki makna kerukunan bermasyarakat yang siya, sekata satu arah dan tujuan.

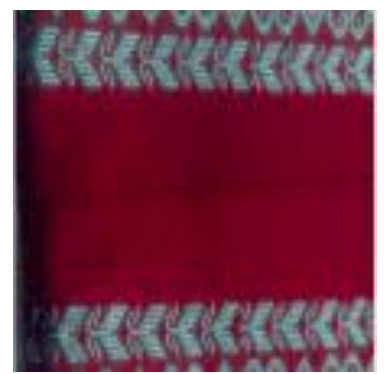

Gambar 15 Bentuk Motif Bada Mudiak

\section{(11) Motif Saluak Laka}

Saluak yaitu pilinan yang saling membantu dan laka yaitu alas periuk yang dibuat dari lidi enau atau lidi kelapa. Pilinan lidi itu dibuat bulat dan dijadikan alas dari periuk. Motif saluak laka memberikan arti bahwa jalinan kemasyarakatan yang kuat akan menjadikan kesamaan dan persatuan untuk memcapai tujuan bersama. Berbentuk layaknya jari Manusia yang saling tumpang tindih

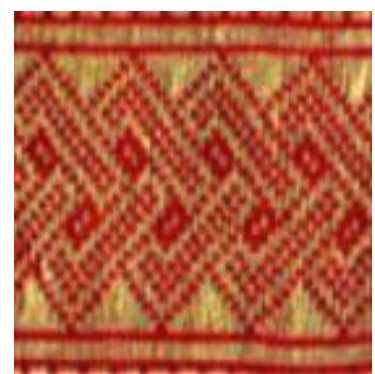

Gambar 16 Bentuk Motif Saluak Laka

(12) Motif cukia baserak

Baserak adalah tidak beraturan. Cukia baserak mengartikan adanya kekacauan
Gorga : Jurnal Seni Rupa

Volume 10 Nomor 02 Juli-Desember 2021

p-ISSN: 2301-5942 | e-ISSN: 2580-2380

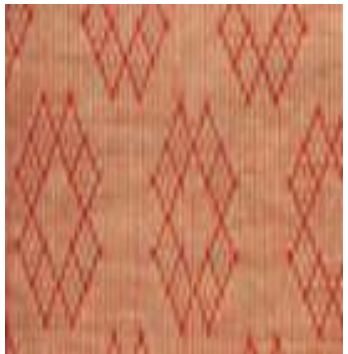

Gambar 17 Bentuk Motif Cukia Baserak

\section{(13) Motif Sirangkak}

Motif sirangkak berbentuk seperti capit kepiting yang disusun sehingga membentuk bunga. Sirangkak yaitu hewan kecil seperti kepiting yang hidup di air tawar dan di rawarawa. Sirangkak mempunyai pencapit untuk melindungi diri. Walaupun jepitan yang ia punya selalu terbuka tapi sirangkak tidak menjepit semua yang ditemuinya, hanya sebagai kewaspadaan terhadap musuh yang diutamakannya. Namun jika diganggu, sirangkak tidak segan-segan untuk menjepit apapun. Kita perlu menerapkan dalam kehidupan kita bentuk dari ketegasan dan jati diri. Jangan pernah mencari masalah dengan manusia lain, tetapi jika orang mengganggu kita maka kita harus kuat dan pantang mundur. Hal inilah arti dari kehati-hatian dan kewaspadaan seperti yang terdapat dalam pepatah Minangkabau musuah indak dicari, basuo pantang dielakkan.

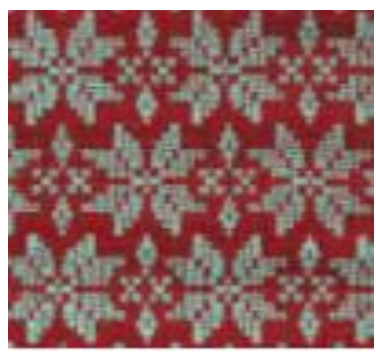

Gambar 18 Bentuk Motif Sirangkak

Berdasarkan hasil observasi penulis, penulis menemukan 13 bentuk motif khas Minangkabau yang ada di Usaha Rino Risal. Yang terdiri dari motif pucuak rabuang, saik kalamai, buah palo, balah kacang, salapah, api, tirai, batang pinang, itiak pulang patang, anyam, bada mudiak, saluak laka, cukia baserak sirangkak.

Motif dapat digolongkan menjadi 3 bagian jika dilihat dari bentuk

(a) Geometris merupakan bentuk yang dapat diukur. Terdiri dari motif pucuk rebung yang distilasi berebentuk segitiga, motif saik galamai berbentuk belah ketupat, motif batang pinang seperti dua garis lurus yang berdekatan, motif buah palo seperti belah ketupat yang didalamnya bergari, motif salapah seperti 
Gorga : Jurnal Seni Rupa

Volume 10 Nomor 02 Juli-Desember 2021

p-ISSN: 2301-5942 | e-ISSN: 2580-2380

belah ketupat yang bersangkutan kiri kanan, motif bada mudiak

(b) Naturalis merupakan bentuk yang meniru bentuk tumbuhan dan hewan terdiri dari motif balah kacang yang di gabungkan menjadi bunga. Motif sirangkak yang berbentuk seperti bunga.

(c) Abstrak merupakan bentuk tidak beraturan terdiri daari motif itiak ulang patang yang berebentuk gelombang, motif cukia baserak, motif saluak laka.

\section{Pembahasan}

\section{1) Desain Motif}

Desain motif merupakan rancangan dalam menciptakan corak hiasan yang akan di jadikan sebuah kain. Desain terdiri dari unsur bentuk, garis, figur yang disusun agar terlihat indah. Desain motif di Usaha Rino Risal berupa gambar motif yang di bentuk sebagai dasar dari pembuatan kain. Bertujuan agar penenun dapat memahami dalam menyungkit/ membentuk motif. Desain motif diperlukan agar konsumen tertarik dan dapat menerima produk tenun yang dihasilkan di Pasar.

Sesuai dengan Doni Rahman(2015) Menuliskan desain adalah atau rencana atau rancangan yang menjadi dasar pembuatan sebuah benda atau karya, Mikke Susanto (2002) dalam buku Diksi Rupa menuliskan bahwa, motif adalah pola, corak, ragam. Motif hias adalah bentuk hiasan pada kain, bagian rumah dan sebagainya., menurut Yuliarma(2016) unsur desain yaitu unsur-unsur yang dipergunakan oleh perancang untuk mewujudkan desainnya agar orang lain dapat menerima dan membaca desain tersebut sesuai seleranya.

Desain motif di Usaha Rino Risal yaitu motif yang terinspirasi dari keseharian masyarakat dan alam Minangkabau. seperti dari hewan, tumbuhan, makanan khas Minangkabau. Sesuai dengan falsafah Minangkabau alam takambang. Tenunan songket biasanya terdiri dari bagian kepala kain, badan kain dan kaki/tepi kain. Pada Usaha Rino Risa Desain motif bagian kepala dan badan selalu diubah agar konsumen tertarik, pada bagian kaki/ tepi kain tidak pernah diubah karena merupakan ciri khas dari tempat Usaha Rino Risal. Masing-masing memiliki pola hiasnya tersendiri.

Menurut Ernawati (2008) pola hias ada 4 bentuk yaitu: (1) pola pinggiran (2)pola mengisi bidang (3)pola serak (4) pola bebas. Selanjutnya menurut Yenni Idrus(2012) secara garis besarnya pola hias dapat dikategorikan menjadi empat yaitu: , pola bebas. pola mengisi bidang, pola hiasan tepi dan pola serak.
Berdasarkan pendapat diatas tempat Usaha Rino Risal menggunakan pola pinggiran pada bagian kepala dan tepi kain sonngket sedangkan pada bagian tengah atau badan songket menggunakan pola serak atau pola mengisi bidang.

\section{2) Bentuk Motif}

Bentuk motif merupakan gambaran atau wujud dari ragam hias. Bentuk motif yang ada pada tenun songket di Usaha Rino Risal berasal dari alam dan keseharian masyarakat Minangkabau. Berdasarkan hasil wawancara yang telah peneliti lakukan, pemilik usaha mengumpulkan bermacam bentuk motif berupa fotokopian dan dari internet.

Sesuai dengan penjelasan oleh ahli Agusti Efi (2019) sumber inspirasi motif tenun adalah makhluk hidup dan lingkungan sekitar. Weni (2014) mengemukakan sumber inspirasi merupakan segala sesuatu yang dapat menimbulkan ide atau gagasan baru sehingga seseorang dapat menghasilkan sesuatu yang baru yang berbeda dari sebelumnya.

Motif Usaha Rino Risal dapat digolongkan menjadi 3 bagian jika dilihat dari bentuk (a) Geometris merupakan bentuk yang dapat diukur. Terdiri dari motif pucuk rebung yang distilasi berebentuk segitiga, motif saik galamai berbentuk belah ketupat, motif batang pinang seperti dua garis lurus yang berdekatan, motif buah palo seperti belah ketupat yang didalamnya bergari, motif salapah seperti belah ketupat yang bersangkutan kiri kanan, motif bada mudiak. (b) Naturalis merupakan bentuk yang meniru bentuk tumbuhan dan hewan terdiri dari motif balah kacang yang di gabungkan menjadi bunga. Motif sirangkak yang berbentuk seperti bunga. (c) Abstrak merupakan bentuk tidak beraturan terdiri daari motif itiak ulang patang yang berebentuk gelombang, motif cukia baserak, motif saluak laka.

Sesuai dengan pendapat Ernawati (2008), reka motif secara umum ada empat yaitu: (1) Bentuk geometris adalah bentuk yang mempunyai bentuk teratur dan dapat diukur. (2) Bentuk naturalis merupakan bentuk yang dibuat berdasarkan bentuk yang ada di alam sekitar. (3) Bentuk dekoratif merupakan bentuk yang berasal dari geometris dan naturalis yang sudah distilasi atau direngga sehingga muncul bentuk baru. Menurut Sedangkan menurut Febriani(2020) Motif tenunan merujuk pada: (1) bentuk geometris. (2) bentuk alam (tumbuh-tumbuhan, binatang, buah-buahan),Bentuk motif tenunan sudah distilasikan sehingga membentuk motif dekoratif pada tenunan. Alifa Hadaf (2016) bentuk motif dikumpulkan menjadi tiga berdasarkan 
aneka jenis ragamhiasnya yakni bentuk geometris, bentuk naturalis dan bentuk dekoratif. Menurut Desma (2012) Mendesain motif mengenakan (reka motif dekoratif) bentuk alam yang sudah disederhanakan juga dapat menirukan bentuk binatang.

\section{KESIMPULAN DAN SARAN}

\section{Kesimpulan}

Setelah menganalisa data yang didapatkan dari hasil wawancara dan observasi langsung dengan kepala dan penenun di tempat usaha tenun songket Minangkabau di tempat usaha rino risal di Kecamatan Koto Tangah Kota Padang, maka dapat diambil kesimpulan sebagai berikut (1)Desain motif yang digunakan pada tenunan songket Minangkabau yaitu motif khas Minangkabau yang berasal dari alam dan keseharian masyarakat Minangkabau. Terdiri dari motif hewan, tumbuhan, dan makanan khas Minangkabau. Desain motif yang dibagikan oleh pemilik kepada pengrajin berbentuk gambar agar pengrajin mudah dalam menyukil / membuat motif tenunan. (2)Bentuk motif yang sering digunakan ditempat usaha rino risal yaitu, motif pucuak rabuang, saik kalamai, buah palo, balah kacang, salapah, api, tirai, batang pinang, itiak pulang patang, anyam, bada mudiak, saluak laka, cukia baserak sirangkak.. Motif Usaha Rino Risal dapat digolongkan menjadi 3 bagian jika dilihat dari bentuk (a) Geometris merupakan bentuk yang dapat diukur. Terdiri dari motif pucuk rebung yang distilasi berebentuk segitiga, motif saik galamai berbentuk belah ketupat, motif batang pinang seperti dua garis lurus yang berdekatan, motif buah palo seperti belah ketupat yang didalamnya bergari, motif salapah seperti belah ketupat yang bersangkutan kiri kanan, motif bada mudiak. (b) Naturalis merupakan bentuk yang meniru bentuk tumbuhan dan hewan terdiri dari motif balah kacang yang di gabungkan menjadi bunga. Motif sirangkak yang berbentuk seperti bunga. (c) Abstrak merupakan bentuk tidak beraturan terdiri daari motif itiak ulang patang yang berebentuk gelombang, motif cukia baserak, motif saluak laka.

\section{Saran}

(1)Diharapkan pemilik usaha rino risal di Kecamatan Koto Tangah Kota Padang untuk lebih meningkatkan pemahaman tentang desain motif, seperti menciptakan yang terbaru yang lebih bervariasi sehingga berbeda dengan motif yang sudah ada di tempat usaha tenun songket di tempat lain atau di pasaran. (2)Diharapkan pemilik usaha dan pengrajin rino risal di Kecamatan Koto Tangah Kota Padang lebih kompak dalam meningkatkan kualitas produk dari pemahaman teknik pembuatan tenunan menambah daya tarik bagi pembeli dan masyarakat umum. (3)Diharapkan kepada pemimpin kota Padang untuk dapat melakukan pelatihan, seminar dan promosi untuk memperkenalkan tenunan songketkepada masyarakat dan untuk mempertahankan kelestariannya. (4)Bagi mahasiswa diharapkan agar lebih termotivasi dalam berwirausaha khususnya dalam tenuanan songket tradisional Minangkabau karena usaha ini sangat bagus jika dikelola dengan baik.

\section{DAFTAR RUJUKAN}

A, Nusyirwan. (1982). Ragam Hias Songket Minangkabau. Padang: Proyek Pembinaan Permuseuman Sumbar.

Biranul Anas, dkk. (2012). Mengenal Tenun Songket Ratu Kain Sumatra Barat. Padang: Dewan Kerajinan Nasional Daerah Provinsi Sumatra Barat.

Budiyono, dkk. (2008). Kriya Tekstil. Jakarta: Depdiknas

Desma, D., Zahri, W., \& Ernawati, E. (2012). Mengingkatkan Aktivitas Siswa dalam Pembelajaran Keterampilan Menghias Sulaman Benang Emas Memalui Model Pembelajaran Kooperatif Tipe Think-pair-share SMPN 1 Kecamatan Payakumbuh. Journal of Home Economics and Tourism, 1(1)

Efi, Agusti (2019). Studi Kasus Motif Tenun Sipirok di Desa Aek Bayur Kota Padang Sidempuan. Jurnal Kapita Selekta Geografi2(7). 64-72.

Ernawati dan Weni Nelmira. (2008). Pengetahuan Tata Busana. Padang: UNP.

Febriani, T dan Efi, A. (2020). Tenunan Songket Balai Panjang Kelurahan Balai Panjang Kecamatan Payakumbuh Selatan. Jurnal Kapita Selekta Geografi3(1). 17-21

Hadaf, A., Adriani, A., \& Novrita, S. Z. (2016). Motif dan Pewarnaan Batik Tulis di Dusun Giriloyo Desa Wukirsari Kecamatan Imogiri Kabupaten Bantul Provinsi Daerah Istimewa YOGYAKARTA (Studi Kasus di Industri Batik Sri Kuncoro). Journal of Home Economics and Tourism, 11(1).

Kartiwa, Suwati. (1986). Ragam Kain Tradisional Indonesia Tenun Ikat. Jakarta: Djambatan

Prastowo, Andi. (2016). Memahami Metode-Metode Penelitian Suatu Tinjauan Teoretis dan Praktis. Jogjakarta: Ar-Ruzz Media

Rahman, Doni. (2015). Ragam Hias Suji Cair Pada Sulaman Salendang Koto Gadang Kabupaten Agam, Sumatera Barat, Padang: UNP

Setiati, Destin Huru. (2008). Membatik. Yogyakarta: PT. MJC 
Susanto, Mikke. (2002). Diksi Rupa. Yogyakarta: Kanisius.

Yuliarma. (2016). The Art of Embriodery Designs. Jakarta: KPG. 